\title{
USO INDISCRIMINADO DE ANTIBIÓTICOS PELA POPULAÇÃO DE SÃO JOSÉ DO CALÇADO (ES) E O PERIGO DAS SUPERBACTÉRIAS
}

\author{
Graziella da Silva MARTINS ${ }^{1}$, Bianca Magnelli MANGIAVACCHI ${ }^{1,2}$, Franz Viana BORGES $^{3} \&$ Nathália \\ Bastos LIMA*
}

\author{
${ }^{1}$ Faculdade Metropolitana São Carlos - Bom Jesus do Itabapoana, Rio de Janeiro, Brasil. \\ ${ }^{2}$ Universidade Estadual do Norte Fluminense Darcy Ribeiro - Consórcio CEDERJ - Polo Bom Jesus do Itabapoana, \\ Rio de Janeiro, Brasil. \\ ${ }^{3}$ Instituto Federal de Educação, Ciência e Tecnologia Fluminense - Campus Campos Centro, Campos dos \\ Goytacazes, Rio de Janeiro, Brasil \\ ${ }^{4}$ Instituto Federal do Norte de Minas Gerais - Campus Salinas, Minas Gerais, Brasil \\ *Autor para a correspondência: nathalia.bioquimica@gmail.com
}

http://dx.doi.org/10.18571/acbm.089

\section{RESUMO}

No decorrer das últimas décadas, a utilização sólida dos antibióticos veio revolucionar o tratamento de doenças infecciosas, permitindo uma grande melhora na saúde da população, reduzindo drasticamente o índice de mortalidade e mobilidade. Porém, hoje em nosso dia a dia está acontecendo uma perda na eficácia dos antibióticos, com o aparecimento de microorganismos resistentes, aumentando a possibilidade de voltarmos à era pré-antibiótica, e as pessoas voltarem a morrer por infecções causadas por bactérias. Novas estratégias de combate à evolução de organismos resistentes a antibióticos devem começar a funcionar, começando a nível municipal, com a informatização da população para o entendimento de como os antibióticos devem ser utilizados, elaboração de um plano de ação para que haja maior vigilância epidemiológica e recomendações para uma prática clínica mais elaborada. O presente trabalho foi desenvolvido com a população de São José do Calçado - ES, no período de junho a setembro de 2015, sendo constituído de 100 pessoas com idade de 20 e 40 anos. Esta pesquisa é do tipo quali-quantitativa e exploratória. Foram aplicados questionários com 15 perguntas fechadas, mantendo o anonimato de todas as pessoas que responderam os mesmos, tendo-se como questão norteadora descobrir "Quais fatores influenciam a população de São José do Calçado, ES, a utilizarem antibióticos de forma indiscriminada?". Verificamos que muitos entrevistados relatam usar esses medicamentos sem prescrição médica e de forma irregular, além de relatar a indicação desses medicamentos para conhecidos. Esses resultados são bastante preocupantes pois indicam a possibilidade de surgimento de bactérias resistentes na região. Com isso, a estratégia de educação em saúde para essa população se faz necessária para a mesma seja instruída sobre o uso correto dos antibióticos.

Palavras-chave: resistência bacteriana, antimicrobianos, educação em saúde, automedicação.

\begin{abstract}
Over the past decades, the solid use of antibiotics revolutionized the treatment of infectious diseases, allowing a great improvement in population health, dramatically reducing mortality and mobility. However, today in our daily life is going a loss in effectiveness of antibiotics, with the emergence of resistant microorganisms, increasing the possibility of return to the pre-antibiotic era, and people returning to die from infections caused by bacteria. New to the evolution of antibiotic resistant organisms' combat strategies shall be started, starting at the municipal level, with the computerization of the population to understand how antibiotics should be used, preparation of an action plan for greater surveillance and recommendations for a more
\end{abstract}


elaborate clinical practice. This work was developed with the population of St. Joseph Footwear - ES, from June to September 2015, consisting of 100 people aged 20 to 40 years. This research is the qualitative and quantitative and exploratory. Questionnaires were administered with 15 closed questions while maintaining anonymity of all respondents the same, having as main question discover what factors influence the population of São José do Calçado, ES, to use antibiotics indiscriminately. We found that many respondents reported using these drugs without a prescription and erratically, and report the indication of these medicines to known. These results are very worrying because they indicate the possibility of emergence of resistant bacteria in the region. Thus, health education strategy for this population is necessary for it to be instructed on the proper use of antibiotics.

Keywords: bacterial resistance, antimicrobial, health education, self-medication.

\section{Introdução}

Segundo dados da Organização Mundial de saúde, infecções representam 25\% das mortes no mundo, e em países em desenvolvimento esse percentual gira em torno de $45 \%$ (WHO, 2010). Isso tem acontecido porque a maior parte da população, obtêm prescrições inadequadas para o uso de antibióticos. Em muitos países dois terços da população usam esse tipo de medicamento sem prescrição médica, por um ou até três dias, interrompendo o tratamento antes da média prevista para uso de medicamentos desse tipo (WHO, 2010).

A descoberta do antibiótico Penicilina, em 1928, aconteceu quando Alexander Fleming ao fazer uma viagem deixou por acaso, uma amostra da bactéria Staphylococcus aureus se contaminada por esporos do fungo Penicillium notatum, a Penicilina, que cresceu dentro da placa impediu o crescimento da bactéria em questão, pois a umidade e o calor daquela época, contribuíram para o crescimento desse bolor (fungo), mas dificultou a reprodutibilidade do experimento, o que acabou por atrasar quase 10 anos o desenvolvimento da Penicilina (AMINOV, 2010).

Com a falta de incentivo, impossibilidade de reproduzir o experimento de maneira considerável e a incapacidade de produzir quantidades maiores de Penicilina estável, que pesquisadores como Flemeng, e até nos anos 30, outros como Paine, Rainstruck e Reid não conseguiram expandir os estudos para o uso da Penicilina (NOVARETTI et al., 2014).Anos mais tarde a Penicilina passou a ser estudada novamente, mas com finalidade quimioterápica sistêmica, por um patologista australiano, Howard Florey (1898-1968), em parceria com o bioquímico alemão Ernert Chain (1906-1979), porem eles não poderiam usá-la em seres humanos.O tempo passou, e Florey e Chain concluíram com sucesso seus estudos, e logo descobriram que a Penicilina era uma substancia química, que se estabilizava ao ser desidratada, e não era uma enzima como Fleming pensava, podendo assim ser transformada em medicamento e com isso puderam salvar milhares de vidas ao longo desses anos.Essa descoberta trouxe um grande avanço para a prevenção e tratamento de doenças no mundo. Sua utilização tem trazido muitas vantagens quando utilizada corretamente, proporcionando grandes benefícios a humanidade (NOVARETTI et al., 2014).

A venda de antibióticos no Brasil supera a venda de outros fármacos como analgésicos/antitérmicos e na última década o aumento da venda de medicamentos genéricos praticamente triplicou (ANVISA, 2012). A venda desses fármacos para pacientes não hospitalares na Europa e na América do Norte, se tornou praticamente restrita, necessitando de prescrição médica, com intuito de impedir o quadro de resistência bacteriana nesses países. No entanto em outras regiões o acesso a esses medicamentos sem prescrição é facilitado contribuindo para a expansão do mercado farmacêutico (VAN BOECKEL et al., 2014) 
Segundo a OMS, os antibióticos têm sido empregados muitas vezes inapropriadamente e, em diversas situações clínicas, sem base em evidencias que comprovem sua real indicação. Os antibióticos são usados desnecessariamente até $60 \%$ dos casos de infecções respiratórias, e em quase $40 \%$ dos casos de diarreia em países em desenvolvimento, uma vez que predominam as infecções virais e/ou parasitarias. Segunda a OMS, o uso de antibióticos mesmo quando são formalmente prescritos, pode ser desnecessário em até 50\% dos casos. (WHO, 2010; NOVARETTI et al., 2014).

O inadequado uso de antibióticos sem critério, sem período, sem dose e sem indicação correta, acelera os mecanismos de defesa das bactérias, fazendo com que o medicamento perca sua eficiência. (PAIVA et al., 2013). As bactérias desenvolvem resistência aos antibióticos numa velocidade maior com que são descobertos e elaborados novos fármacos (SILVA et al., 2011).

A resistência bacteriana refere-se à capacidade das bactérias se multiplicarem na presença de antibióticos em doses mais altas que as que contêm em doses ministradas em pacientes. Tratase de um processo biológico natural que surgiu com a utilização desses fármacos no tratamento de infecções (WANNMACHER, 2004) e, que devido ao uso irracional e indiscriminado desses em humanos e animais, tem aumentado cada vez mais (SANTOS, 2004).

O genoma e as triagens de coleções de compostos em detrimento as triagens de produtos naturais microbianos foram as principais ferramentas entre os anos de 1980 a 2000 para a busca de novos antibióticos. Mas, logo pode se perceber que havia uma redução drástica na identificação de novos protótipos antibióticos, no mesmo instante que ocorria um aumento na incidência de resistência bacteriana. (GUIMARÃES et al., 2010).

No Brasil, já foram notificados casos de "superbactérias", intituladas dessa forma por serem organismos multirresistentes aos antibióticos existentes e, como consequência, a Agência Nacional de Vigilância Sanitária (ANVISA) determinou a publicação de medidas regulatórias, publicadas em outubro de 2010, com o propósito de reduzir a exposição da população aos antibióticos e, com isso, combater a resistência bacteriana (SILVA-CARVALHO et al., 2009). Essa determinação inicialmente provocou uma redução significativa nas vendas de antibióticos no país, no entanto em 2012 os números voltaram a crescer atingindo valores apresentados nas medidas regulatórias, mantendo assim o elevado nível de comercialização desses medicamentos (SINDUSFARMA, 2012).Assim, as infecções causadas por micro-organismos mutantes resistentes, tendem a comprometer o tratamento de pacientes fazendo com que estes tenham que prolongar o mesmo, elevando os custos e aumentando o risco de morte além de contágio de outras pessoas com essas "superbactérias".

Esse trabalho teve como objetivo identificar, através de questionários aplicados na população de São José do Calçado, ES, informações que contribuam para a elaboração e execução de projetos socioeducativos voltados para reeducação a respeito do uso inapropriado de antibióticos, podendo evitar um possível aumento em casos de resistência bacteriana nessa sociedade.Nesse trabalho tem-se como questão norteadora descobrir "Quais fatores influenciam a população de São José do Calçado, ES, a utilizarem antibióticos de forma indiscriminada?"

\section{Material e Métodos}

O presente trabalho foi desenvolvido com a população de São José do Calçado ES, no período de junho a setembro de 2015, em 100 pessoas com idade de 20 e 40 anos. Esta pesquisa é do tipo quali-quantitativa e exploratória. Foram aplicados questionários com 15 perguntas fechadas (Apêndice A), mantendo o anonimato de todas as pessoas que responderam os mesmos, para analisar a concepção que as pessoas dessa localidade têm sobre o uso de antibióticos.

Os resultados dos questionários aplicados na cidade de São José do Calçado ES foram reunidos para análise e depois transformados em gráficos comparativos, possibilitando observar os principais pontos preocupantes do uso indiscriminado de antibióticos por essa 
população.Após a análise dos resultados e gráficos, foi elaborado um banner educativo que será doado para ser exposto na Unidade de Saúde II (USII), localizada no centro de São José do Calçado ES, com finalidade de orientar as pessoas de como e quando elas devem usar o antibiótico sem colocarem em risco a sua saúde.

\section{Resultados e Discussão}

Todos os resultados referentes a essa pesquisa encontram-se nas Figuras 1 e 2 desse trabalho. Quando analisadas as respostas para a primeira afirmativa presentes no questionário aplicado, nota-se que a maioria dos entrevistados possuem o conhecimento que o antibiótico é um medicamento (Figura 1A) e para $45 \%$ dos entrevistados vírus, bactérias, fungos e protozoários são organismos muito diferentes, no entanto $17 \%$ discordam dessa afirmativa (Figura 1B).Mais da metade dos entrevistados discordam queos antibióticos podem ser utilizados apenas em infecções bacterianas, e apenas $18 \%$ dos entrevistados concordaram totalmente com essa afirmação (Figura 1C).

Sobre a afirmativa de um antibiótico específico ser capaz de matar todos os tipos de bactérias, 39\% concordaram com essa afirmativa, e em contrapartida $23 \%$ discordaram da mesma (Figura 1D). Trinta e oito por cento afirmara que parar o tratamento antes do prazo determinado pelo médico pode piorar a infecção e mais da metade $(59 \%)$ afirmaram também que o uso incorreto de antibióticos poder favorecer o surgimento de bactérias mais fortes (Figura 1E e $1 F)$.

Oitenta e dois por cento dos entrevistadosrelataram já terem utilizaram antibióticos sem receita médica, enquanto menos de 5\% relataram que não (Figura $1 \mathrm{G}$ ). Outra questão levantada nos questionários foi se os entrevistados já pararam o tratamento feito com antibiótico antes do prazo prescrito pelo médico, e nesse caso $49 \%$ dos entrevistados relataram já terem feito e apenas $22 \%$ discordaram da mesma (Figura $1 \mathrm{H}$ ). 

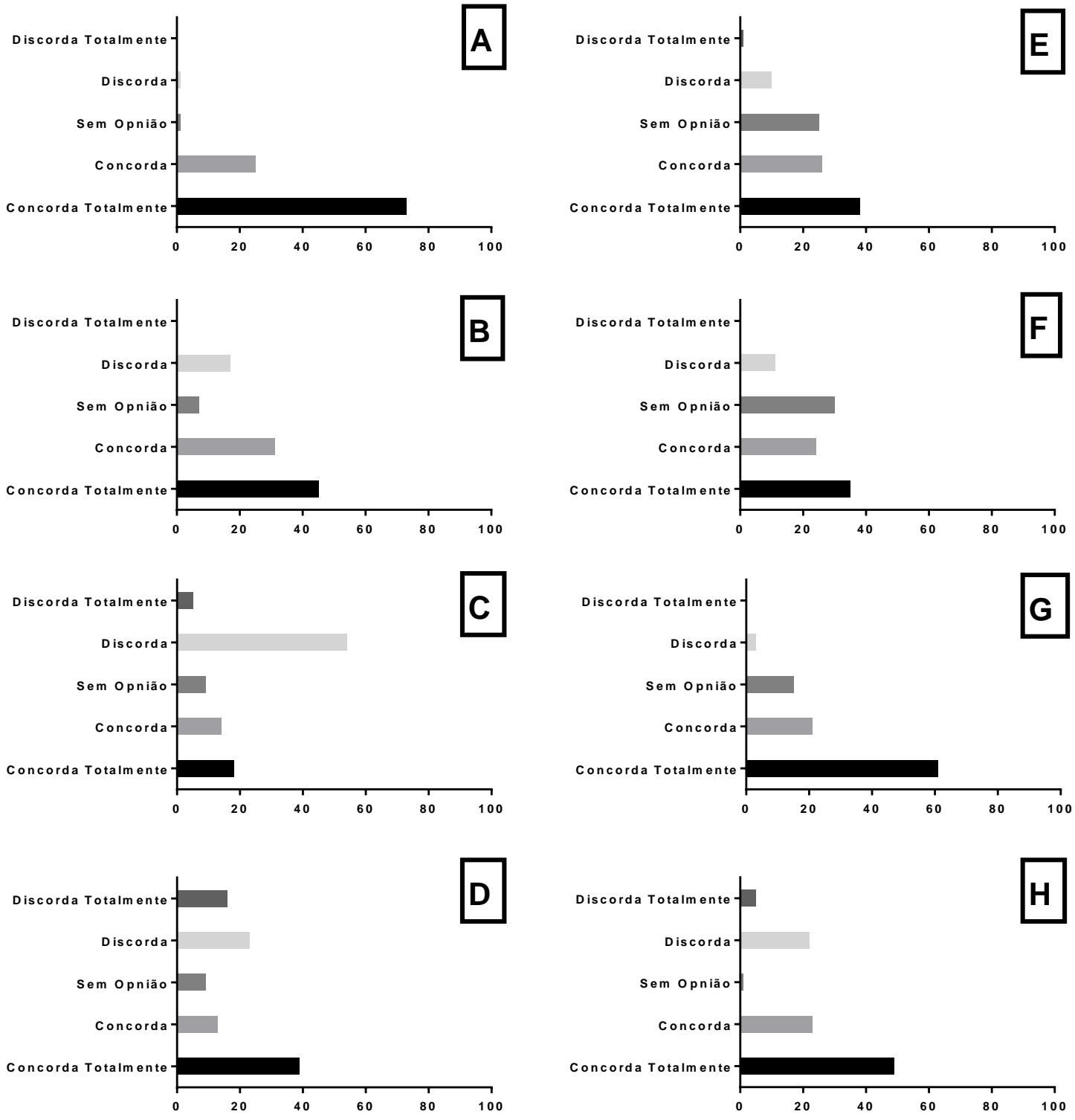

POR CENTAGEM

Figura 1. Porcentagem de respostas referentes as afirmações presentes no questionário: (A) afirmação 1: Antibiótico é um medicamento. ;(B) afirmação 2: Apesar de causarem doenças, vírus, bactérias, fungos e protozoários são muito diferentes. ;(C) afirmação 3:Antibióticos podem ser utilizados apenas em infecções bacterianas. ; (D) afirmação 4:Um antibiótico específico é capaz de matar todos os tipos de bactérias. ; (E) afirmação 5:Parar o tratamento antes do prazo determinado pelo médico pode piorar a infecção. ; (F) afirmação 6:O uso incorreto dos antibióticos pode favorecer o surgimento de bactérias mais fortes. ; (G) afirmação 7:Já usei antibiótico sem receita médica; $(\mathrm{H})$ afirmação 8:Já parei o tratamento antes do prazo prescrito.

Ao perguntar os entrevistados se eles fazem uso de antibióticos frequentemente $53 \%$ discordaram da afirmação e apenas cerca de 35\% afirmaram fazer uso do medicamento (Figura 2A). Quando questionados se sempre que tem uma infecção usam antibióticos 38\% dos entrevistados concordaram totalmente e $22 \%$ concordaram e em oposição $31 \%$ discordaram dessa afirmativa (Figura 2B).

Ao serem questionados se indicaram um antibiótico para um amigo a maioria discordaram da afirmativa (Figura 2C) no entanto 46\% dos entrevistados relataram que já 


\section{Biomédica Brasiliensia}

ISSN: 2236-0867

fizeram uso de antibiótico indicado por amigos enquanto que apenas $20 \%$ discordaram dessa afirmativa (Figura 2D) e ainda cerca de 54\% relataram que não considerarem o uso de antibióticos perigoso e somente $28 \%$ discordaram da mesma dessa afirmativa (Figura 2E).

Quando questionados sobre não considerarem que a utilização de antibióticos oferece risco à saúde, $40 \%$ dos entrevistados concordaram totalmente com esta afirmativa e $15 \%$ concordaram, em contrapartida apenas $20 \%$ discordaram totalmente da mesma (Figura 2F).Quando perguntados se concordam que as pessoas usam os antibióticos de forma correta $41 \%$ dos entrevistados discordaram e apenas 10\% concordaram totalmente (Figura 2G).
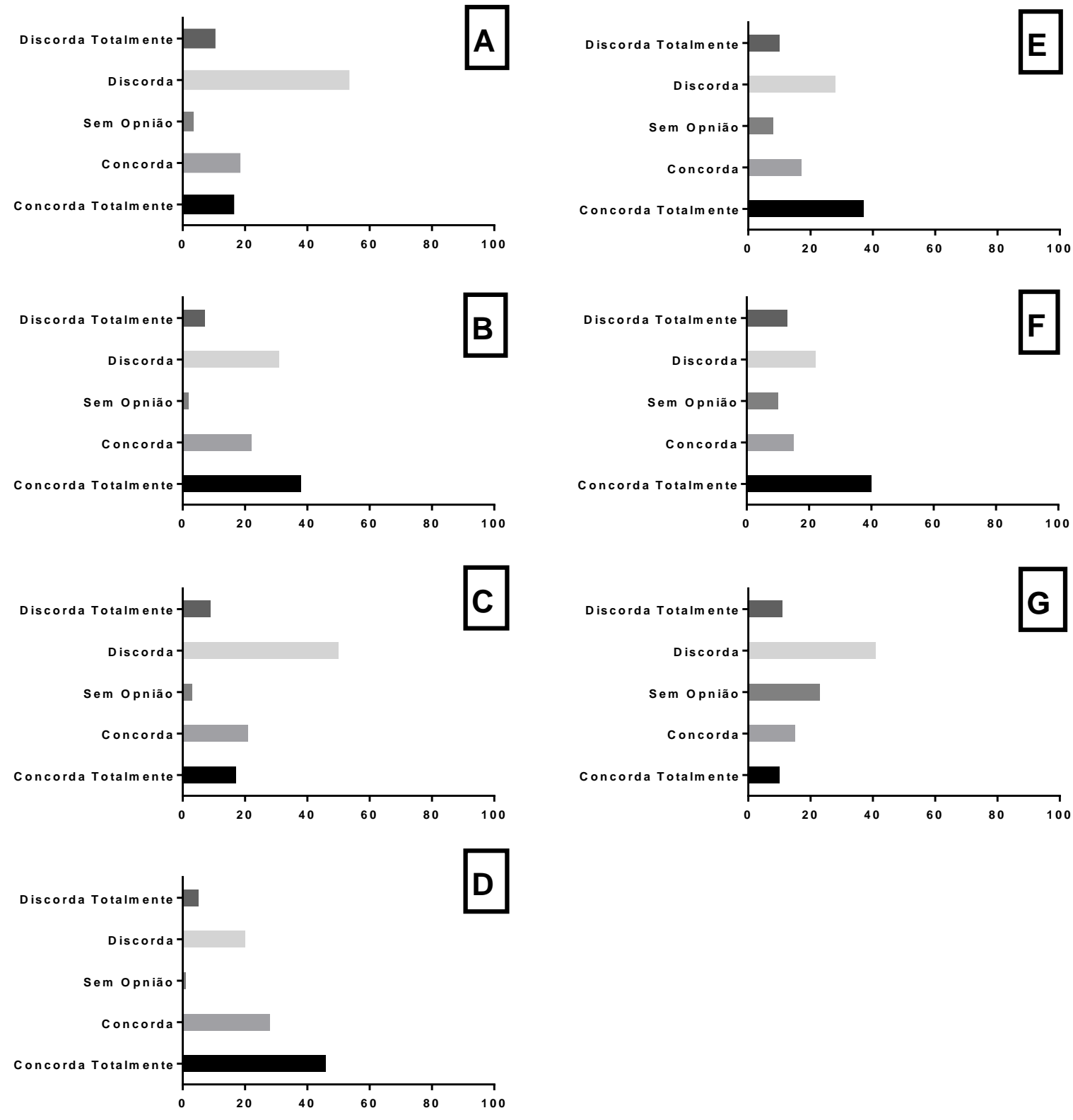

PORCENTAGEM

Figura 2. Porcentagem de respostas referentes as afirmações presentes no questionário: (A) afirmação 9: Uso antibiótico frequentemente.; (B) afirmação 10:Sempre que tenho uma infecção uso antibiótico.; (C) afirmação 11:Já indiquei um antibiótico para um amigo.; (D) afirmação 12:Um amigo já me indicou um antibiótico.; (E) afirmação 13:Não considero o uso de antibióticos perigoso.; (F) afirmação 14:Não considero que a utilização de antibióticos oferece risco para a saúde.; $(\mathrm{G})$ afirmação 15:Acho que as pessoas usam antibióticos de forma correta, seguindo o médico. 


\section{Discussão}

São José do Calçado localiza-se na região Sul do Estado do Espírito Santo. Entre os estabelecimentos de saúde presentes no município encontra-se a Unidade de Saúde II, Dr. Aristides Teixeira de Rezende, fundada em 1991 conforme Lei n ${ }^{\circ}$ 737/91, e esta instituição está inscrita no Cadastro Nacional de estabelecimentos de Saúde (CNES) desde março de 2002. (SMSSJC, 2010). A Unidade de Saúde II atende usuários residentes na sede e distritos (Airituba, Alto Calçado e Divino Espírito Santo) com clientela proveniente da zona urbana e rural, além da população oriunda dos municípios adjacentes que compõem o ABC do Sul do Espírito Santo, ou seja, Apiacá e Bom Jesus do Norte (SMSSJC, 2010).

Os resultados presentes nesse estudo mostram que a maioria da população sabe que os antibióticos são fármacos e os mesmo dizem serem capazes de identificar que os diferentes micro-organismos causadores de doenças apresentam características que são diferentes, porém mesmo assim, de forma equivocada, afirmam esses fármacos poderiam ser usados em qualquer tipo de infecção que não somente as causadas por bactérias (Figura 1A-C).

Após análise de resultados da pesquisa, pode-se dizer que, um dos principais fatores que contribuem para o uso inadequado de antibióticos pela população de São José do Calçado - ES é a facilidade que as pessoas têm em adquirir esse tipo de medicamento. Neste estudo, 39 pessoas concordaram totalmente e 13 concordaram com afirmação de que usam antibióticos específicos para matar todos os tipos de bactérias, ou seja, 52\% concordam com essa afirmativa (Figura 1D). Porém, sabemos que quanto mais frequente for à administração desse fármaco de forma inadequada pela população maior a chance de se desenvolver cepas resistentes a estes.

Wannmacher (2004) diz que as indicações de tratamentos com antibióticos deveriam seguir critérios bem definidos para diminuir a difusão que a resistência bacteriana e o surgimento de potencias efetivos adversos. No Brasil, o uso irracional dos medicamentos é fortemente influência por questões como a automedicação e a propaganda e publicidade tendenciosas, que como consequência pode ocasionar intoxicações e até mortes. (DANDOLINI, 2012).

Outro fato de grande relevância para essa discussão é que a população compra esse tipo de medicamento sem nenhum tipo de fiscalização rigorosa, e essas mesmas pessoas representam $72 \%$ da população ( $49 \%$ concordam totalmente e $23 \%$ concordam) que param o tratamento com esses fármacos antes da de um prazo mínimo de 8 dias de tratamento recomendado por médicos, assim que os sintomas desaparecem o tratamento é interrompido, e apesar dessa grande maioria saber dos riscos as mesmas continuam parando o tratamento antes do prazo prescrito (Figura 1E e 1H).Os antibióticos têm sido empregados muitas vezes inapropriadamente e, em diversas situações clínicas, sem base em evidências que comprovem sua real indicação. (NOVARETTI, 2014).

A eficiência na ação dos antibióticos pode ficar comprometida se os mesmos não forem ingeridos de acordo com o horário determinado, pois os medicamentos permanecem no organismo por um determinado período de tempo, devendo suas doses serem administradas com rigidez como foram descritas. A ingestão do medicamento de forma incorreta faz as bactérias se adaptarem e se multiplicarem, aumentando e promovendo a resistência aos antibióticos. (CHAVES et al., 2008).

E com um número significativo e ao mesmo tempo preocupante a maior parte dessa população, representada por $59 \%$ dos entrevistados sabe que o uso incorreto de antibióticos pode favorecer o surgimento de bactérias mais fortes, porém a maioria ainda usa esses fármacos sem receita médica (Figura $1 \mathrm{~F}$ e $1 \mathrm{G}$ ).

A maioria dessa mesma população afirma não usar antibiótico frequentemente, mas faz uso desse medicamento sempre que tem uma infecção, independente de qual é o tipo, causada por vírus, ou outros organismos (Figura 2A e 2B). O consumo desenfreado de antibióticos, sem uma cuidadosa avaliação das suas corretas indicações pode levar ao crescimento do número de 
cepas resistentes, ou seja, acarretar em mutações seletivas. É preciso desenvolver novos métodos de diagnóstico das doenças infecciosas, bem como educar médicos e leigos sobre o uso criterioso desses fármacos (NICOLINI et al., 2008).

Nascimento (2003) destacou que além da resistência aos antibióticos oferecem risco de toxidade ao organismo humano, o qual está relacionado às doses administradas, que podem exceder a real necessidade do organismo. Outro risco à saúde que o autor traz são as reações de hipersensibilidade à sensibilização do indivíduo ao antibiótico. Segundo Mota et al., (2005), os prejuízos que os antibióticos podem causar a saúde humana incluem efeitos tóxicos diretos, indução a alergias além da resistência bacteriana.

A grande maioria dos entrevistados sabe que os antibióticos devem ser usados apenas com indicação médica, ainda assim 55\% dos entrevistados não consideram que a utilização dos mesmos oferece risco a saúde (Figura 2F-G). Apesar de não considerarem o uso de antibióticos perigoso, a maioria dos entrevistados nunca indicou o uso de antibiótico para amigos, mas uma parcela representativa de $74 \%$ já usou antibiótico indicado por algum amigo (Figura 2C e 2E). O uso indiscriminado de antibióticos na comunidade e dentro dos hospitais é uma das maiores causas de resistência bacteriana no Brasil. Hoje, a pessoa que tem febre toma antibiótico, se tem um vírus que fica no organismo menos de $48 \mathrm{~h}$ toma antibiótico, além de usar as sobras de antibióticos guardadas em casa para tratar outras doenças. (PAIVA, 2013).

A grande oferta desse tipo de medicamento, acompanhado pela facilidade em adquiri-lo sem receita médica potencializa o seu uso e cria a necessidade de elaborar programas e/ou projetos socioeducativos sobre as consequências desastrosas que a resistência aos antibióticos pode trazer a toda população como, aumento da mortalidade, gastos ainda maiores na saúde e a facilidade na transmissão e expansão desse problema. Para que isso não ocorra é necessário orientar a sociedade de maneira clara e instrutiva, com informações técnicas e cientificas, por meio de vídeos informativos e atividades educacionais, para racionalizar o uso de antibióticos, mostrando os problemas que eles podem trazer se usados de maneira inadequada.

Para Naves \& Silver (2005), umas das estratégias para minimizar o problema relacionado ao uso inadequado dos antibióticos seria a de esclarecer as dúvidas do usuário, garantindo, assim, que este adquira conhecimento referente à sua administração, apresentando a partir daí uma favorável adesão ao tratamento. A educação continuada de prescritos e a padronização da prescrição de antibióticos constituem estratégias de grande importância para promover o uso racional de antibiótico (OLIVEIRA \& MUNARETTO, 2010) e além disso iniciativas locais, como a nossa, e como apresentadas em outros estudos locais sobre avaliação da efetividade e da promoção de programas de educação em saúde focadas na educação em saúde possam incentivar mais pesquisadores e assim contribuir definitivamente para a obtenção de mais dados sobre o conhecimentos em nossa região (RAGGI \& MANGIAVACCHI, 2015; BERTONCELI et al., 2014).

\section{Conclusão}

Cada vez mais, as pessoas têm feito o uso abusivo de antibióticos, principalmente pela facilidade em adquirir esse medicamento. Esse costume não está diretamente ligado à falta de conhecimento das pessoas sobre os riscos que esse uso inadequado dos antibióticos pode trazer, visto que uma parcela razoável da população sabe alguma coisa sobre eles, mas continuam mantendo esse hábito negligente.

A maioria das pessoas continua com esse hábito inadequado, com finalidade de acabar com uma dor rapidamente, associando a facilidade em se comprar o medicamento sem receita, são influenciados muitas vezes por indicação de amigos e/ou parentes. Mas esquecem que cada organismo possui uma reação diferente para cada substância. 
Assim, as pessoas têm deixado de comparecer ao médico para obter um diagnóstico e uma prescrição adequada, para assumir os riscos da automedicação.

Porém, o uso indiscriminado de um antibiótico pode desencadear um processo de seleção natural, potencializando o aparecimento de uma população bacteriana com cepas resistentes, tornando seu tratamento cada vez mais difícil. A facilidade em adquirir esse medicamento em farmácias, sem prescrição médica, fazendo uso inadequado, em doses incorretas, e em períodos diferenciados, que podem ser muito perigosos, são ações que tem facilitado o surgimento dessas cepas mais resistentes.

Os antibióticos são poderosos medicamentos contra bactérias capazes de provocar infecções e tem sido de grande utilidade para salvar vidas o mundo inteiro, porém seu uso inadequado pode gerar o rompimento de opções de tratamento em consequência da resistência bacteriana.Nesse sentido, é importante que haja sempre ações permanentes voltadas à educação em saúde, que sejam de ordem prática e efetiva capazes de envolver toda a comunidade sendo mantidas por programas públicos ou governamentais para que situações como esta descrita em nosso estudo sejam minimizadas.

\section{Referências}

AMINOV, R. I. A Brief History of the Antibiotic Era: Lessons Learned and Challenges for the Future. Frontiers in Microbiology, 1, 134, 2010.

ANDRADE, D.; LEOPOLDO, V.; HAAS, V. Ocorrência de bactérias multirresistentes em um centro de Terapia Intensiva de um Hospital brasileiro de emergências. Revista Brasileira Terapêutica Intensiva. v.18, n.1, p.4-14, 2006.

ANVISA. 2012. Resolução da Diretoria Colegiada - RDC nº 20, de 05 de maio de 2012. Dispõe sobre o controle de medicamentos à base de substâncias classificadas como antimicrobianos, de uso sob prescrição, isoladas ou em associação. Diário Oficial da União de 09 de maio de 2012, (seção 1): 39-40.

AZEVEDO, E. F., BARBOSA, L. A., De, S. H., \& CASSIANI, B. Administração de Antibióticos por via Subcutânea: Uma Revisão Integrativa da Literatura. ACTA Paulista de Enfermagem. v. 25, n.5, p. 817-822, 2012.

AZEVEDO, E. F., BARBOSA, L. A., De, S. H., \& CASSIANI, B. Administração de antibióticos por via subcutânea: uma revisão integrativa da literatura. Acta Paulista deEnfermagem. v. 25, n. 5, p. 817-22, 2012.

BERTONCELI, M. A. A.; LIMA, N. B.; BORGES, F. V. Análise Do Conhecimento da Problemática da Tuberculose por Profissionais de Saúde do Município de Apiacá, ES..Acta Biomedica Brasiliensia , v. 5, p. 79-97, 2014.

BERGAMASCHI, C. Interações medicamentosas: analgésicos, antiinflamatórios e antibióticos. Revista de Cirurgia e Traumatologia. v.7, n.2, p.9-18, abr./jun. 2007.

BRAOIOS, A. PEREIRA, A. C. S. BIZERRA, A. A. POLICARPO, O. F. SOARES, N. C. BARBOZA, A. S. Uso de Antimicrobianos pela população da cidade de Jataí (GO). Revista Ciência \& Saúde Coletiva. v. 18, n. 10, p. 3055-3060, 2013. 
CHAVES, E. M. C., QUEIROZ, M. V. O., ALMEIDA, P. C., MOREIRA, T. M. M., \& VASCONCELOS, S. M. M. Problemática da administração de antimicrobiano em recémnascidos. Revista da Rede de Enfermagem do Nordeste. v.9, n.3, p. 62-67, jul. /Set., 2008.

CORREA, A.D.; CAMINHA, J.R.; SOUZA, C.A.M.; ALVES, L.A. Uma abordagem sobre o uso de medicamentos nos livros didáticos de biologia como estratégia de promoção de saúde. Revista Ciência \& Saúde Coletiva. v.18, n.10, p.3071-3081, 2013.

CUNHA, C. R., PELLEGRIN, L., \& STEIN, A. T. Uso racional de antibióticos para médicos de atenção primária. Revista Associação Médica do Rio Grande do Sul. v.48, n.2, p. 126-134, abr./jun. 2004.

DANDOLINI, B. W., BATISTA, L., de SOUZA, L. H. F., GALATO, D., \& PIOVEZAN, A. P. Uso Racional de Antibióticos: uma experiência para educação em saúde com escolares. Ciência \& Saúde Coletiva. v.17, n. 5, p. 1323-1331, 2012.

FERREIRA, M. V. C.; PAES, V. R.; LICHTENSTEIN, Arnaldo. Penicilina: oitenta anos. Revista de Medicina de São Paulo, v. 87, n. 4, p. 272-276, 2008.

GRILlO, V. T. R. D. S., GONÇAlveS, T. G., JÚNIOR, J. D. C., PANIÁGUA, N. C., \& TELES, C. B. G. Incidência bacteriana e perfil de resistência a antimicrobianos em pacientes pediátricos de um hospital público de Rondônia. Revista Ciências Farmacêuticas Básica e Aplicada. v.34, n.1, p. 117-123, 2013.

GUIMARÃES, D. O., MOMESSO, L. D. S., \& PUPO, M. T.. Importância Terapêutica e Perspectivas para a Descoberta e Desenvolvimento de Novos Agentes. Química Nova. v.33, n.3, p. 667-679, 2010.

GURGEL, T.\& CARVALHO, W. A Assistência Farmacêutica e o aumento da resistência bacteriana aos antimicrobianos. Revista Latin American Journal of Pharmacy. v. 27, n.1, p. 118-123, 2008.

KADOSAKI, L. L. SOUSA, S. F., BORGES, J. C. M. Análise do uso e da resistência bacteriana aos antimicrobianos em nível hospitalar. Revista Brasileira de Farmácia. v.93, n.2, p.128-135, 2012.

LOURO, E; LIEBER, N. S. R.; RIBEIRO, E. Eventos adversos a antibióticos em pacientes internados em um hospital universitário. Revista Saúde Pública. v.41, n.6, p. 1042-1048, 2007.

MARQUES, T.; REIS, A.; SILVA, A.; GIMENES, F.; OPITZ, S.; TEIXEIRA, T.; LIMA, R.; CASSIANI, S. Erros de administração de antimicrobianos identificados em estudo multicêntrico brasileiro. Revista Brasileira de Ciências Farmacêuticas. v.44, n.2, p.305-314, abr./jun., 2008.

MARTINS, N. SOUSA, L. M. G.,TORRES, M. L. D., FIRMO, W. C. A. Análise de prescrição médica de antibióticos de uma farmácia comercial do município de Imperatriz - MA. Revista Científica do ITPAC. v.7, n.4, p. 1-9, out. 2014.

MELO. D.O.; RIBEIRO. E; STORPIRTIS, S. A importância e a história dos estudos de utilização de medicamentos. Revista Brasileira de Ciências Farmacêuticas. v. 42, n. 4, p. 475485, out./dez. 2006. 
MONTEIRO, C., FONTES, A., MATOS, R., RODRIGUES, A. I., PEREIRA, P., \& COSTA, M. D. C. Utilização de Antibióticos numa amostra da população de Lisboa. Revista Lusófona de Ciências e Tecnologias da Saúde. v. 7, n.1, p.21-35, 2010.

NICOLINI, P.; NASCIMENTO, J.; GRECO, K. e MENEZES, F. Fatores relacionados à prescrição médica de antibióticos em farmácia pública da região Oeste da cidade de São Paulo. Revista Ciência \& Saúde Coletiva. v. 13, n. Supl. p.689-696, 2008.

NOVARETTI, M. C. Z., AQUINO, S., \& PISCOPO, M. R. Controle de Vendas de Antibióticos no Brasil: Análise do efeito dos atos regulatórios no uso abusivo pelos consumidores. Revista Acadêmica São Marcos. v.4, n.2, p. 25-39, jul. /Dez., 2014.

OLIVEIRA, A. L., SOARES, M. M., SANTOS, T. C., \& SANTOS, D. MECANISMOS DE RESISTÊNCIA BACTERIANA A ANTIBIÓTICOS NA INFECÇÃO URINÁRIA. UNINGÁ Review, v. 20, n. 3, 2014.

OLIVEIRA, K. DESTEFANI, S. Perfil da Prescrição e dispensação de antibióticos para crianças em uma Unidade Básica de Saúde (UBS) no município de Ijuí - RS. Revista de Ciências Farmacêuticas Básica e Aplicada. v. 32, n.3, p. 395-401, 2011.

OLIVEIRA, K. MUNARETTO, P. Uso racional de antibióticos: Responsabilidade de Prescritores, Usuários e Dispensadores. Revista Contexto \& Saúde. v.9, n.18, p. 43-51, jan. /jun.,2010.

PAIVA, C. L., ZANI, L. B., DUARTE, I. D., \& JONIS-SILVA, M. D. A. Uso Indiscriminado de Antibióticos e Superbactérias KPC: Temas CTS Controverso no Ensino de Biologia. Revista Eletrônica Debates em Educação Científica e Tecnológica. v.03, n.01, p. 32-40, junho de 2013.

RAGGI \& MANGIAVACCHI. Programas de hipertensão arterial no brasil: um relato de caso sobre o município de São José do Calçado - ES. Acta Biomedica Brasiliensia. v. 6, n 1, p. 5667 Jul. 2015.

RIBEIRO, F., SILVA, S. R., VICENTE, I. N., \& ALMEIDA, S. Prescrição Antibiótica no Serviço de Urgência Pediátrica de um hospital Nível II da região Centro. Revista Nascer e Crescer. v.22, n. 4, p. 216-219, 2013.

RODRIGUES, M. \& OLIVEIRA, L. Erros na administração de antibióticos em unidade de terapia intensiva de hospital de ensino. Revista Eletrônica de Enfermagem. v.12, n. 3, p. 511$519,2010$.

ROSA, M. B.; PERINI. E.; ANACLETO. T. A.; NEIVA. H. M.; BOGUTCHI. T. Erros na prescrição hospitalar de medicamentos potencialmente perigosos. Revista Saúde Pública. v.43, n.3, p. 490-498, 2009.

SANTOS, M. V., de LOYOLA, G. S. I., de MORAES, M. L. C., \& LOPES, L. C. A eficácia dos contraceptivos orais associados ao uso de antibióticos. Revista Ciências Médicas. v.15, n. 2, p. 143-149, mar. /abr., 2006. 
SANTOS, V. \& NITRINI, S. Indicadores do uso de medicamentos prescritos e de assistência ao paciente de serviços de saúde. Revista Saúde Pública. v.38, n.6, p.819-826, 2004.

SÃO JOSÉ DO CALÇADO, ES. SECRETARIA MUNICIPAL DE SAÚDE. ADMINISTRAÇÃO 2009-2012. Nov. 2010.

SILVA-CARVALHO, M.C., BONELLI, R.R., \&SOUZA, R.R..Emergence of multiresistant variants of the community-acquired methicillin-resistant Staphylococcus aureus lineage ST1SCC mec IV in 2 hospitals in Rio de Janeiro, Brazil. Diagnostic Microbiology and Infectious Disease, 65: 300-305, 2009.

SILVA, D. N. D. R., GALATO, D., \& ALANO, G. M.Análise do Conhecimento e opinião da população sobre a atual regulamentação para a venda de antibióticos no Brasil. Cadernos Acadêmicos. v.4, n.2, p.218-221, ago. /Dez, 2012.

SINDUSFARMA. Antibióticos voltam a ter crescimento de vendas, aponta pesquisa[internet] 4 de maio de 2012. Disponível em: http://farmaefarma.blogspot.com.br/2012/05/antibioticosvoltam-ter-crescimento-de.html.Acesso em 09 de dezembro de 2015.

TERRİVEL, J.; RODRIGUES, A.T.; FERREIRA, M.; NEVES, C.; ROQUE, F.; SILVA, O.; FIGUEIRAS, A.; HERDEIRO, M.T. Conhecimento dos médicos relativo prescrição de antibióticos e à resistência microbiana: estudo piloto de comparação questionário online VS papel. Revista de Epidemiologia e Controle de infecção. v.3, n.3, p. 93-98, 2013.

TRAVASSOS, I. \& MIRANDA, K. Resistência Bacteriana como consequiência do uso inadequado de antibióticos. Revista Informa. v.22, n. 5/6, p.54-59, 2010.

VAN BOECKEL, T.P. GANDRA, S., ASHOK, A., CAUDRON, Q., GRENFELL, B. T., LEVIN, S. A., \& LAXMINARAYAN, R.Global antibiotic consumption 2000 to 2010: ananalysis of national pharmaceutical sales data. The Lancet Infectious Diseases, 14(8):742 $750,2014$.

WANNMACHER, L. Uso indiscriminado de antibióticos e resistência microbiana: Uma guerra perdida? Revista Uso Racional de Medicamentos: temas selecionados. v.1, n. 4, p. 1-6, mar. 2004. 


\section{Apêndice A}

Prezado (a) entrevistado (a), esta pesquisa é parte das exigências para obtenção do título de Licenciado em Biologia (FAMESC), e tem como objetivo avaliar seu conhecimento a respeito do uso correto de antibióticos.

Escolaridade:

Idade:

Sexo: M ( _ $)$ F ( _ ). Bairro:

Para as questões abaixo marque a opcão que melhor representa sua opinião.

1. Antibiótico é um medicamento.

( ) Concorda totalmente

( ) Sem opinião

( )

Discorda totalmente

( ) Concorda

( ) Discorda

2. Apesar de causarem doenças, vírus, bactérias, fungos e protozoários são muito diferentes.
( ) Concorda totalmente
( ) Sem opinião
( ) Discorda totalmente
( ) Concorda
( ) Discorda

3. Antibióticos podem ser utilizados apenas em infecções bacterianas.

\begin{tabular}{|c|c|c|c|c|c|}
\hline ) & Concorda totalmente & ( & Sem opinião & & Discorda totalmente \\
\hline ) & Concorda & ( & Discorda & & \\
\hline
\end{tabular}

4. Um antibiótico específico é capaz de matar todos os tipos de bactérias.
( ) Concorda totalmente
( ) Concorda
( ) Sem opinião
( ) Discorda totalmente

5. Parar o tratamento antes do prazo determinado pelo médico pode piorar a infecção.

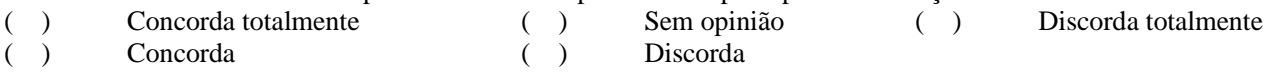

6. O uso incorreto dos antibióticos pode favorecer o surgimento de bactérias mais fortes.

$\begin{array}{lllll}\text { ( ) Concorda totalmente } & (\text { ) } & \text { Sem opinião } & \text { ( ) Discorda totalmente } \\ \text { ( ) Concorda } & (\text { ) } & \text { Discorda }\end{array}$

7. Já usei antibióticos sem receita médica.

$\begin{array}{llll}\text { ( ) Concorda totalmente } & \text { ( ) } & \text { Sem opinião } & \text { ( ) } \\ \text { ( ) Concorda } & (\text { ) } & \text { Discorda } & \end{array}$

8. Já parei o tratamento antes do prazo prescrito.

$\begin{array}{llll}\text { ( ) Concorda totalmente } & \text { Concorda } & \text { Sem opinião } & \text { ( ) }\end{array}$

9. Uso antibiótico frequentemente.

$\begin{array}{llll}\text { ( ) Concorda totalmente } & \text { ( ) } & \text { Sem opinião } & \text { ( ) Discorda totalmente } \\ \text { ( ) }\end{array}$

10. Sempre que tenho uma infecção uso antibiótico.

$\begin{array}{llll}\text { ( ) Concorda totalmente } & (\text { ) } & \text { Sem opinião } & \text { ( ) Discorda totalmente }\end{array}$

11. Já indiquei um antibiótico para um amigo.

$\begin{array}{llll}\text { ( ) Concorda totalmente } & \text { ( ) } & \text { Sem opinião } & \text { ( ) Discorda totalmente }\end{array}$

12. Um amigo já me indicou um antibiótico.

$\begin{array}{llll}\text { ( ) Concorda totalmente } & \text { ( ) } & \text { Sem opinião } & \text { ( ) Discorda totalmente } \\ \text { ( ) Concorda } & (\text { ) } & \text { Discorda }\end{array}$

13. Não considero o uso de antibióticos perigoso.

$\begin{array}{llll}\text { ( ) Concorda totalmente } & \text { Sem opinião } & \text { ( ) Discorda totalmente }\end{array}$

14. Não considero que a utilização de antibióticos oferece risco para a saúde.
( ) Concorda totalmente
( ) Sem opinião
( ) Discorda totalmente
( ) Concorda
( ) Discorda

15. Acho que as pessoas usam antibióticos de forma correta, seguindo o médico.

$\begin{array}{llll}\text { ( ) Concorda totalmente } & (\text { ) } & \text { Sem opinião } & \text { ( ) Discorda totalmente } \\ \text { ( ) Concorda } & (\text { ) } & \text { Discorda }\end{array}$ 